\title{
Finite Reinsurance: How does it Concern Supervisors? Some Efficiency Considerations in the Light of Prevailing Regulatory Aims*
}

\section{Sebastian von Dahlen}

International Association of Insurance Supervisors (IAIS), c/o Bank for International Settlements, Centralbahnplatz 2, Basel BS CH 4002, Switzerland.

E-mail: sebastianvondahlen@gmx.net

Finite reinsurance transactions attracted the attention of insurance supervisors and beyond recently. This paper considers the resulting and ongoing discussion concerning the regulatory environment for finite reinsurance transactions. Consumer protection and financial stability are reflected in the light of cost-benefit considerations as criteria for the further design of finite reinsurance-related regulation and supervision. At the same time, some of the forces that influence the shaping of regulation and supervision are described. This article concludes that few, concise and, in an ideal case, worldwide applicable rules and principles are best suited to guide the development within the field of finite reinsurance. Such rules and principles would most probably have a positive impact on consumer protection and financial stability. This article therefore supports the IAIS intention to consider the topic of finite reinsurance further.

The Geneva Papers (2007) 32, 283-300. doi:10.1057/palgrave.gpp.2510137

Keywords: finite reinsurance; regulation and supervision; effectiveness and efficiency; consumer protection; financial stability; International Association of Insurance Supervisors

\section{Introduction}

A sufficient transfer of risks from the ceding insurer to the reinsurer and appropriate accounting are essential for the legitimacy of finite reinsurance transactions. Worldwide media coverage arose when the large Australian insurer HIH collapsed in March 2001. It is widely believed that finite reinsurance contracts inflated the financial picture of the insurer FAI prior to its acquisition by HIH in 1998. This misrepresentation may have obscured financial problems at FAI, which may have ultimately contributed to the HIH collapse. Following the failure of HIH, a Royal Commission was assigned to inquire into the company's collapse. The Commission tabled its report ${ }^{1}$ to the Australian Parliament on 16 April 2003. Moreover, according to press reports the New York State Attorney General Eliot Spitzer and the Securities

\footnotetext{
* The views expressed in this article are those of the author and do not necessarily represent the views of the IAIS, BIS or any affiliated institution.

${ }^{1}$ Royal Commission (2003).
} 
and Exchange Commission (SEC) ${ }^{2}$ investigated the "questionable use"3 of finite reinsurance concerning a transaction "in the late 2000 between General Re, a Berkshire affiliate, and AIG, the world's leading insurance company". 4

It remains an open question whether cases such as these could jeopardize the trust of an average customer in insurance products, if not his/her confidence in the overall capital market. This is, particularly so, where extended media coverage prevails.

However, supervisors have an additional reason to be concerned about finite reinsurance arrangements. A ceding insurer that buys insurance coverage reduces in the case of an insured event its need for capital at hand. Capital relief for the ceding insurer is therefore reasonable. At the same time, such relief is only appropriate if significant risk is transferred to the reinsurer. The ceding insurer would otherwise receive supervisory capital relief without significantly reducing its risk exposure.

Finite reinsurance is a generic term. There is no clear-cut line between finite reinsurance and non-finite reinsurance (traditional reinsurance) because finite reinsurance criteria are also found in non-finite reinsurance products. The appellation "finite reinsurance" is appropriate since the respective contracts typically exhibit a finite or limited amount of risk to which the reinsurer is exposed. However, a restriction in the amount of risk transferred from the ceding insurer to the reinsurer is by no means an exclusive feature of finite reinsurance arrangements.

Various institutions have provided a definition of "finite reinsurance". 5 The following definition for the purpose of this paper is considered, especially the reasoning at the two largest reinsurance markets, Europe ${ }^{6}$ and the U.S., ${ }^{7}$ as well as the characterization of the IAIS: ${ }^{8}$ finite reinsurance is a form of reinsurance arrangement under which a ceding insurer transfers only a limited amount of risk, relative to the aggregated premiums, to the reinsurer.

This paper uses the term regulation to refer to the overall framework for insurance and reinsurers, which is typically specified by rules and principles. We use the term supervision to indicate the enforcement of given rules and principles. However, the perceived meaning of the expressions "supervisor" and "regulator" varies to some extent among jurisdictions. Therefore, this text refers to, whenever appropriate, to "regulatory and supervisory measures".

Different aspects of an appropriate transfer of risks are considered in the following section. The impact of sufficient transparency and disclosure is revisited. This includes thoughts on the shortcomings of the currently often applied 10-10 approach. As an example, we provide an illustration of the so-called high severity-low frequency insured events, such as natural catastrophes. Furthermore, the particular issues of minor risk transfers, for example a risk transfer below 1 per cent, are considered.

\footnotetext{
${ }^{2} \mathrm{SEC}$ is the agency responsible for administering federal securities laws in the U.S.

${ }^{3}$ O'Brien (2005).

${ }^{4}$ Ibid.

${ }^{5}$ A preliminary summary of definitions is to be found at IAIS (2006a, Appendix III).

${ }^{6}$ EU Directive (2005).

${ }^{7}$ NAIC (2006).

${ }^{8}$ IAIS (2006a, pp. 5 and 28).
} 
The next section elaborates on the efficiency of finite reinsurance regulation and supervision. Consumer protection and financial stability are considered as criteria to evaluate regulatory and supervisory efficiency. Some of the driving forces behind deregulation or regulation are thereby also exhibited. Along that line, that section considers the demand for finite reinsurance-related regulation by displaying our preliminary empirical findings.

The penultimate section presents conclusions concerning finite reinsurance-related regulation and supervision in the light of cost-benefit considerations. According to our considerations, a few well-elaborated, clear and concise rules and principles would be preferable.

In the final section, this paper then summarises our findings and provides an outlook.

\section{Towards a transparent relocation of risks}

Despite potential concerns to the contrary, finite reinsurance arrangements are and have to be legitimate. An infinite transfer of risks from the ceding insurer to the reinsurer could pose a threat to the latter. At the same time, supervisors typically require a minimum transfer of risk from the ceding insurer to the reinsurer. The rationale behind this requirement is two-fold. First, in many instances the ceding insurer receives supervisory capital relief, if it buys reinsurance coverage. Second, under existing national and international accounting rules the ceding insurer typically receives favourable accounting treatment, if a finite transaction is recorded on the balance sheet as reinsurance and not as credit.

The motivation for the accounting treatment is straightforward. Both a credit and a reinsurance transaction affect the balance sheet of participating actors in a quite different way for obvious reasons. A credit agreement usually comprises a repayment requirement that binds the ceding insurer. The ceding insurer has to reimburse the reinsurer at an agreed upon point in time. Under a conventional reinsurance arrangement, the ceding insurer buys the right to a specified reimbursement from the reinsurer, if the insured event occurs.

\section{Transparency and disclosure}

Stock taking and analysis of existing data on reinsurers is at the heart of IAIS transparency considerations. ${ }^{9}$ Furthermore, the IAIS also aims at specifically facilitating appropriate analysis and disclosure with respect to the finite reinsurancerelated risk transfer. ${ }^{10}$ Public disclosure refers to the format of risk-oriented notifications. Standardized formats enhance the comparability and thereby increase transparency. At the same time, improved public disclosure would most probably facilitate the harmonization of finite reinsurance regulation and supervision. ${ }^{11}$

\footnotetext{
${ }^{9}$ IAIS (2006b); Mørup (2006, pp. 19-20); IAIS (2004, p. 32).

${ }^{10}$ IAIS (2006a).

${ }^{11}$ IAIS (2004, p. 32).
} 
286

A sufficient degree of disclosure and transparency is a prerequisite for both microprudential and macroprudential ${ }^{12}$ supervisory perspectives. Supervisory evaluations concerning the solvency of a specific (re-)insurer will only be possible if the total amount of accepted and ceded risks is traceable at the respective company (microprudential perspective). The solvency position would be blurred if an insurer falsely claims that it ceded major risks. A blurred picture of the overall resilience of the global reinsurance market (macroprudential perspective) could hypothetically emerge if a number of major companies were able and willing to display a "sugar-coated risk position".

\section{Risk transfer}

Currently, various jurisdictions apply a supervisory approach which involves two steps. The first step aims at determining whether the amount of risk shifted from the ceding insurer to the reinsurer is above or below a defined risk transfer threshold. As a second step, all reinsurance contracts that pass the risk transfer threshold receive beneficial supervisory and accounting treatment. The outcome of this two-step approach is binary. The two possible outcomes are: either a contract is entirely accounted for as reinsurance and the ceding insurer receives the full regulatory capital enhancement, or a reinsurance arrangement is such that a ceding insurer receives no capital enhancement at all and it is not accounted for as reinsurance. In the latter the transaction is accounted for as a credit.

\section{0-10 approach}

To determine a risk transfer threshold, the so-called 10-10 rule has been used as a basis. It denotes a 10 per cent probability of a 10 per cent loss on ceded reinsurance premiums. Figure 1 displays the basic structure of the 10-10 rule. A specific (re-)insurance contract can be identified by a point within the diagram. Such a point would characterize the "probability of loss" and the "loss on ceded reinsurance premium" of the specific (re-)insurance contract. The black field enclosed by the lines A and I. characterizes finite reinsurance contracts, which fail to meet any of the two requirements for a sufficient risk transfer. Neither the obligatory probability of loss nor the required loss on ceded reinsurance premiums is available at finite reinsurance contracts indicated by the black field. The striped areas highlight contracts that do not meet one of the two requirements. A contract specified by a point within the lower striped area (II and A) would display a loss probability below the minimum requirement of 10 per cent. A contract that satisfies both requirements is exemplarily characterized by point $\mathrm{K}$.

However, the 10-10 approach is a "rule of thumb" which is not codified under Generally Accepted Accounting Principles (GAAP), International Financial Reporting Standards (IFRS) or current statutes. The minimum risk transfer threshold would be as low as 1 per cent, since the 10-10 rule denotes a multiplicative relation, which can

\footnotetext{
${ }^{12}$ Knight (2006) and also Borio (2003).
} 


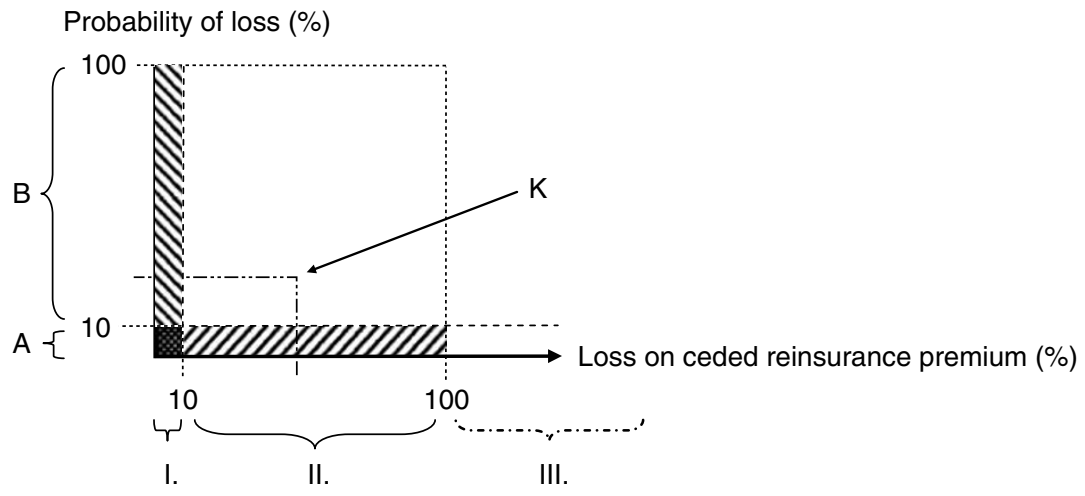

Figure 1. Illustration of the 10-10 rule. A similar graph is to be found in von Dahlen (2006, p. 14).

be expressed by the following term:

$$
10 \% \times 10 \%=(0.1 \times 0.1=0.01)=1 \% .
$$

The limitations of the $10-10$ requirement have been highlighted repeatedly. ${ }^{13}$ Of major concern are, for example, NatCat treaties. The latter provide insurance protection for low probability/high severity events, such as severe Natural Catastrophes (NatCat). Even traditional NatCat treaties regularly comprise a probability of loss, which is significantly lower than 10 per cent. At the same time, an insured NatCat event typically comprises a loss that is much higher than a 10 per cent loss on ceded reinsurance premiums.

\section{Expected reinsurer deficit (ERD) approach}

Figure 2 focuses on insured NatCat events. Insurance contracts that cover such extreme events are exemplarily represented by the points $\mathrm{C}$ and $\mathrm{D}$.

Curve $\mathrm{R}$ represents a line that describes the ERD. According to the ERD approach, the NatCat treaty $\mathrm{C}$ could be regarded as appropriate concerning the transferred amount of risk, whereas the amount of risk transferred by NatCat treaty D would be below the ERD requirement and could hence be considered as inappropriate. Concerning the supervisory treatment of NatCat treaties, the ERD is regarded as a potential solution. Other than the 10-10 rule the ERD approach considers the amount of resulting risk transfer, regardless of specific probability and regardless of specific loss on ceded reinsurance premium. An example would be a 2.5 per cent probability of a 40 per cent loss on ceded reinsurance premiums:

$$
2.5 \% \times 40 \%(=0.025 \times 0.4)=1 \% .
$$

The requirement "resulting risk transfer $\geqslant 1$ per cent" would be satisfied.

\footnotetext{
${ }^{13}$ Casualty Actuarial Society (2005).
} 


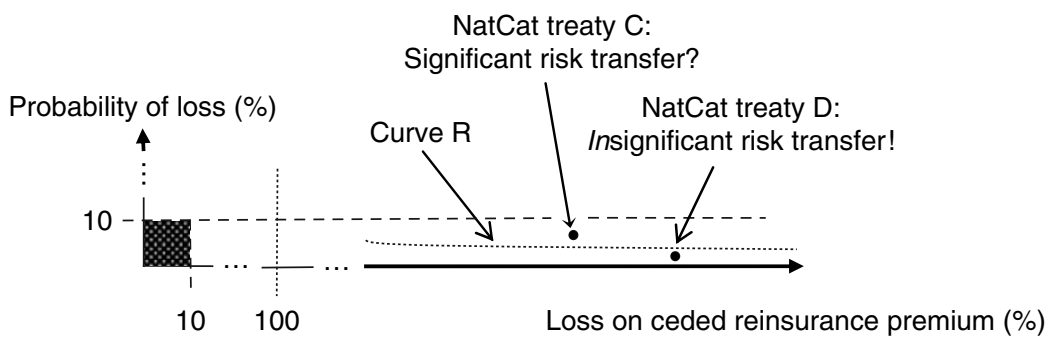

Figure 2. Some specifics of NatCat treaties. A similar graph is to be found at in von Dahlen (2006, p. 15).

Furthermore the ERD approach, which is indicated by curve R in Figure 2, would incorporate the tail value at risk (TVaR) and thus include the loss potential in the right tail of the distribution, thereby covering the specific distributions that are relevant for catastrophe reinsurance. Despite its clear advantages, the ERD approach, however, is not without restrictions. The American Academy of Actuaries, for example, stated that it would be inappropriate to apply the ERD approach as a bright-line standard test. ${ }^{14}$

\section{Regulatory approaches}

Figure 3 summarises the risk transfer - related outcome of different regulatory regimes. The crucial point within curve $\mathrm{A}$ is a risk transfer of 1 per cent $\left(E_{1}\right)$. Reinsurance contracts that comprise a risk transfer of below 1 per cent would not entitle the participating companies, according to curve A, to (re-)insurance accounting and a supervisory capital relief. At a minimum risk transfer of 1 per cent and above, the ceding insurer could record the contract in the balance sheet as a reinsurance contract and receive the respective full supervisory capital relief. The ceding insurer receives either no benefit or the entire benefit. Curve A describes therewith a binary structure. Curve B by contrast characterizes a gradually increasing benefit. An additional risk transfer results in increased benefits (compare $A R$ and $C R$ ) for the ceding insurer. Point $E_{2}$ characterizes, for example, a risk transfer, $R T$, of $(1+\mathrm{w}) \%$ from the ceding insurer to the reinsurer. The ceding insurer would thereby receive a capital relief $(\mathrm{CR})$ of $Z \%$. It is within the scope of the accounting profession to provide a solution on how different amounts of risk transfer along curve $\mathrm{B}$ should be represented appropriately in the balance sheet of the involved companies.

Curve B would go with a more risk-oriented regulatory and supervisory system. Such a system is currently considered under Solvency II within the CEIOPS ${ }^{15}$ framework of the European Union.

\section{Minor risk transfer revisited}

It remains a challenge to determine a reasonable threshold below which a risk transfer would not be recognized by supervisors. ${ }^{16}$ Among the questions to be considered are

\footnotetext{
${ }^{14}$ American Academy of Actuaries (2005).

${ }^{15}$ Committee of European Occupational Pension and Insurance Supervisors.

${ }^{16}$ IAIS (2006a, p. 47); American Academy of Actuaries (2005).
} 


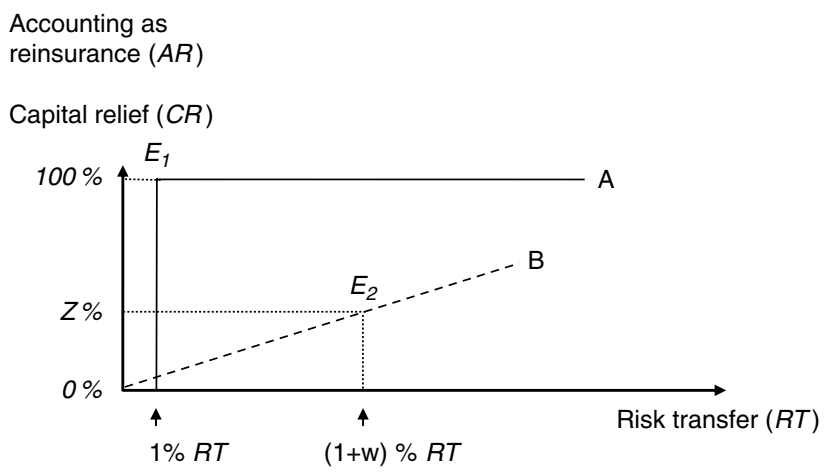

Figure 3. Accounting treatment and supervisory relief dependent on risk transfer.

the following: Should a risk transfer threshold, for example 1 per cent, be applied to all situations? Should there be differentiations between, for example, non-life and life finite reinsurance arrangements? What happens if reinsurance contracts comprise a risk transfer in the range between: $0 \%<R T<1 \%$ - especially under a regime which is characterized by the above curve B?

It could be a logical step to allow for capital relief $(C R)$ even within the just mentioned band of risk transfer $(0 \%<R T<1 \%)$, if a risk-based supervisory regime is applied. Within the latter, a potential $C R$ could be in accordance with the actual risk transfer $(R T)$. However, supervisory review and verification could be an issue in this bracket that includes very small amounts of risk transfer. The closer the value of the specific $R T$ comes towards 0 per cent, the harder it is to find a methodologically sound risk transfer measurement approach.

Instead of trying to achieve a sound measurement of ever smaller and smaller amounts of transferred risk, one could revisit the risk transfer from a different angle. According to the IAIS guidance paper on finite reinsurance, "specific contractual obligations of the ceding insurer" could be considered as a criterion to discriminate between a reinsurance treaty on the one hand and a loan or deposit on the other hand. As said by the IAIS paper a treaty should be regarded "as a loan or deposit, if during its regular development, the cedant has the unconditional obligation to indemnify the reinsurer for any negative balances that may arise out of the treaty relationship. All liabilities must be contingent on the proceeds of the underlying insurance business". ${ }^{17}$

\section{Efficiency considerations concerning finite reinsurance regulation and supervision}

A two-step approach could be helpful to assess the effectiveness and the efficiency of prevailing and intended regulation. From an economic point of view, it is reasonable to consider the efficiency of a specific regulatory approach only as a second step. The

${ }^{17}$ IAIS (2006a, p. 12). 
first step should always be the answer to the question whether specific regulatory and supervisory measures are effective. Given a clearly defined target the regulatory approach, which incurs the lowest direct and indirect costs, would be efficient. However, such considerations could in some instances also conclude that no-regulation and/or self-regulation is preferable to the provisions of state law.

In recent years, various public organizations concerned with regulation and supervision commented broadly on the potential impact of regulation. ${ }^{18}$ In addition to that, prominent industry representatives provided specific reinsurance regulation related considerations. ${ }^{19}$ According to Nikolaus von Bomhard, Chairman of the Board of Management of Munich Re, "future standards on risk-based capital management should be based on a small set of principles". ${ }^{20}$ Walter B. Kielholz, Chairman of Credit Swiss Group and Vice-Chairman Swiss Re Group stated that it is crucial to "ensure that new regulations are based on a clear economic rationale". ${ }^{21}$ Along that line, James J. Schiro, Chief Executive Officer of Zurich Financial Services, wrote lately that "regulatory interventions must be designed to meet economically sound goals". ${ }^{22}$ Specifically with respect to finite reinsurance Barry suggested that regulators should reduce the incentive to purchase finite reinsurance by not allowing financial statement benefits concerning these arrangements. ${ }^{23}$ Culp and Heaton indicated that a reduction of regulatory benefits could be associated with decreased supervisory requirements. ${ }^{24}$ In the middle of the leading proponents, who specifically advocate further steps towards harmonization and clarification is Thomas Steffen, Chief Executive Director of insurance supervision within the Federal Financial Supervisory Authority (BaFin): "We advocate that the IAIS go even further and adopt internationally accepted standards above and beyond the requirements stated in the current Guidance Paper". 25

In the light of the above reflections, this section provides considerations concerning the aim of optimal regulation. Moreover, the so-called market model of regulation and supervision is applied to characterize the demand for regulation and deregulation. Finally this section provides our preliminary empirical data concerning the demand for finite reinsurance - related regulation and supervision.

\section{Consumer protection and financial stability}

The aim of consumer protection has a long-lasting tradition. Insurance supervisors have existed in some countries for more than 100 years. Based on the sometimes unequal balance of power between a customer and an insurer, consumer protection is often regarded as a value in itself. There is an additional rationale for some degree of insurance regulation and supervision, if a society has a system of social security in

\footnotetext{
${ }^{18}$ For example, European Commission (2006); OECD (2006); Renda (2006) and the therein cited literature.

${ }^{19}$ Nebel (2002).

${ }^{20}$ Von Bomhard and Frey (2006, p. 47).

${ }^{21}$ Kielholz and Nebel (2005, p. 35).

${ }^{22}$ Schiro $(2006$, p. 25$)$

${ }^{23}$ Barry (2004, p. 13).

${ }^{24}$ Culp and Heaton (2005).

${ }^{25}$ Fromme (2006, p. 17).
} 
place. The system of social security would have to support the victims of bankrupt insurers, for example, if persons lose their retirement provisions due to insolvency. The overall costs of the social security system would increase if the system had to support additional persons.

Financial stability ${ }^{26}$ considerations address rather the resilience of the overall (re-)insurance market, if not the entire financial system. Political attention towards potential instability is amplified especially due to the increasing complexity of financial systems during the last 15 years or so. The World Bank and the IMF are among the institutions that have invested resources into the development of financial soundness indicators. ${ }^{27}$ However, it has recently been observed that a widely recognized definition of financial stability is currently not available. ${ }^{28}$ Nevertheless, the ability to withstand shocks is regarded as a key element of financial stability.

Systemic risk is an issue, if the failure of one institution affects a wider part of the financial system (and beyond), through a contagion mechanism. ${ }^{29}$ The worldwide reinsurance market repeatedly demonstrated its capacity to absorb the negative outcome of large insured catastrophes, as recently demonstrated during the Hurricane season 2005, which comprised Rita, Wilma and Katrina. ${ }^{30}$

The textbox below provides a hypothetical example where systemic considerations are not only relevant to the financial system but also with respect to the real economy.

Textbox: Contagion - hypothetical exemplification of a cause-and-effect chain

Considering spill-over from the financial market into the real economy

Reports on conditions of financial instability in the banking sector could induce a decreasing risk appetite at major reinsurers. As a consequence, some reinsurers could reduce their risk exposure. Hence they would no longer accept specific peak risks, which are usually ceded from primary insurers to reinsurers. Pharmaceutical companies are an example of a field of business where high risk exposures prevail. Primary insurers, which sell insurance protection against pharmaceutical risks, have to cede (some of) the peak risks to reinsurers. Under an extreme scenario, such a primary insurer could no longer offer insurance protection for the pharmaceutical industry, if the appropriate reinsurance protection were no longer available. This could hurt both the ongoing business in the pharmaceutical sector and also further innovations. As a result, the real economy would be impaired.

The following subsection provides a theoretical framework to analyse supply and demand for regulatory and supervisory measures.

\footnotetext{
${ }^{26}$ For a summary of definitions, see Schinasi (2004).

${ }^{27}$ For example, Avesani (2005); World Bank and IMF (2005); IMF (2003); Das et al. (2003).

${ }^{28}$ Trichet (2005).

29 Diamond and Dybvig (1983).

${ }^{30}$ IAIS (2006b); Fender and Wooldridge (2005); IAIS (2005).
} 


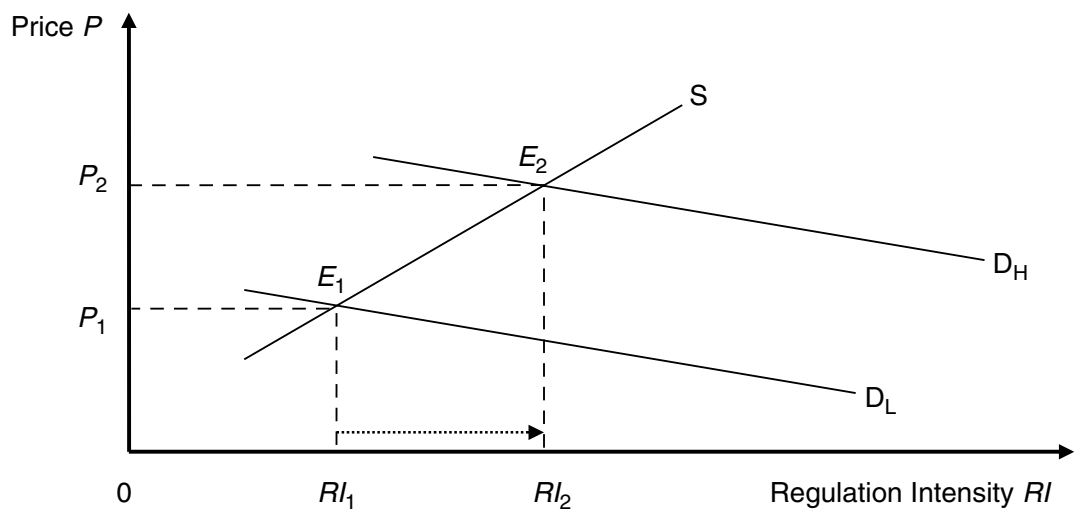

Figure 4. Market model concerning regulation. Similar considerations are to be found in Zweifel and Eisen (2000, p. 361).

\section{Considerations on the driving forces of regulation and supervision}

A very comprehensive economic analysis of insurance regulation and supervision is to be found in Zweifel and Eisen. ${ }^{31}$ The so-called "market model" (cf. Figure 4) of insurance regulation and supervision seems best suited to explain processes that involve regulation as well as deregulation. ${ }^{32}$ Increased supply $(S)$ of regulation comes typically at an overall higher cost, potentially comprising regulation-related efficiency losses. A likely reason for an increase in the demand for regulation $(D)$ would be the insolvency of several major insurers that harms a large group of insurance customers. On the other hand, it could be due to a changing market environment in which, for example, a small group of strong and influential insurers shows a clearly reduced willingness to pay for supervisory measures. Such a change could cut the demand for regulation from a higher level, $D_{H}$, to a lower level, $D_{L}$. Considerations concerning a substitution of regulatory and supervisory activity with an increased reliance on market forces have been discussed previously with respect to the solvency regime. ${ }^{33}$

The two cases indicated above (HIH and AIG), in particular, which involved finite reinsurance contracts, provoked debate about the respective regulation and supervision. It is reasonable to assume that the finite reinsurance-related regulation intensity (RI) will increase as a result, for example from $R I_{1}$ to $R I_{2}$, thereby moving the equilibrium between demand and supply from $E_{1}$ to $E_{2}$. Accordingly the price $(P)$ would increase from $P_{1}$ to $P_{2}$.

Finally the envisaged security level of insurers is a political decision. An insurance supervisor, which aims at entirely avoiding potential bankruptcies of insurers, would most likely require a very tight and thereby costly supervisory regime. If such a tight regime requires prior approval for each finite reinsurance contract,

\footnotetext{
${ }^{31}$ Zweifel and Eisen (2000).

32 Ibid.; Adams and Tower (1994); Peltzman (1976); Stigler (1971).

${ }^{33}$ Rees et al. (1999).
} 


\begin{tabular}{|c|l|c|}
\hline Solution & Answer & Preference $^{*}$ \\
\hline A & $\begin{array}{l}\text { Current regulatory/supervisory advantages concerning finite } \\
\text { reinsurance and associated regulatory/supervisory measures }\end{array}$ & 16 \\
\hline B & $\begin{array}{l}\text { Reduced regulatory/supervisory advantages concerning finite } \\
\text { reinsurance and reduced regulatory/supervisory measures }\end{array}$ & 8 \\
\hline
\end{tabular}

Figure 5. Preferences concerning regulatory advantages and associated supervisory measures. *These amounts are based on the number of experts, who disclosed their respective preference.

innovations ${ }^{34}$ could decrease, since it would be easier for insurers to apply for solutions that have been approved previously.

Some empirical data on the demand for finite reinsurance-related regulation and supervision

We consider that in some instances insurance regulation and supervision implies not only direct costs but also direct benefits for the affected insurer. To elaborate on this consideration our paper presents some preliminary empirical data. The data were collected while the author participated as a speaker and as a member of the regulatory roundtable at a conference on finite reinsurance. ${ }^{35}$ Experts from the industry, comprising, among others, representatives of different reinsurers, were asked which of the following two solutions they would prefer: (A) "Current regulatory/supervisory advantages concerning finite reinsurance and associated regulatory/supervisory measures", or (B) "Reduced regulatory/supervisory advantages concerning finite reinsurance and reduced regulatory/supervisory measures". Answers were received from a total of 24 respondents, as shown in Figure 5.

Our preliminary data point towards the notion that there is some preference for the current structure of the supervisory approach to finite reinsurance, although the latter comes at some cost for the supervised entities.

Nevertheless, the empirical example should not blur the fact that there are quite different perspectives concerning cost-benefit considerations. Despite being preliminary, the received answers are in all probability based on the perspective of the companies that participated at the London meeting. It is therefore appropriate if the perspectives of different stakeholders are considered concerning prevailing and envisaged finite reinsurance regulation and supervision.

\section{The challenge of cost-benefit considerations}

Efficiency and cost-benefit considerations are a challenging task. Ideally, policymakers could identify those finite reinsurance-related regulatory and supervisory

\footnotetext{
${ }^{34}$ Caruana (2005).

35 "C5 Advanced Conference on Finite \& Structured Risk Reinsurance - Purchasing, Selling and Structuring Risk in a Complex Regulatory Environment”, London, May 2006.
} 
measures that enable the envisaged aim at the lowest cost. However, both identification and measurement of finite reinsurance-related costs and benefits are quite demanding. A comparison of the most favourable - according to cost and benefit considerations - regulatory solution on the one hand with approaches that reach beyond government imposed regulation and supervision on the other hand could identify additional solutions. An example would be mechanisms of self-regulation induced by market forces.

Let us denote by $R S_{\text {opt }}$ the optimal regulatory/supervisory solution. Moreover, let different regulatory states be characterized by $k$, with $k=1, \ldots, n$. With little loss of generality, we assume that each regulatory and supervisory state features a specific combination of regulatory/supervisory benefit $\left(B_{k}\right)$ and regulatory/supervisory cost $\left(C_{k}\right)$. Therefore, $R S_{\text {opt }}$ should be identified by the largest sum of all $B_{k}-C_{k}>0$. The optimal regulatory/supervisory solution should hence be characterized by the following equation:

$$
R S_{\text {opt }}=\max \left\{B_{1}-C_{1}, \ldots, B_{n}-C_{n}\right\} .
$$

Both costs and benefits include direct $(D)$ and indirect $(I)$ components, which are specified by

$$
B_{k}=\left(B_{k D}+B_{k I}\right) \text { and } C_{k}=\left(C_{k D}+C_{k I}\right)
$$

respectively. Direct costs $\left(C_{k D}\right)$ are comparatively easy to measure, since they are somehow quantifiable by supervisory authorities and supervised entities. An example of indirect costs arising from regulation $\left(C_{k I}\right)$ would be obstacles to economically beneficial innovations within the reinsurance market and beyond. Moreover, an avoidance of appropriate finite reinsurance contracts could also result in a suboptimal macroeconomic risk allocation. Despite some preliminary results, ${ }^{36}$ the quantification of direct $\left(B_{k D}\right)$ and indirect $\left(B_{k I}\right)$ regulatory benefits is yet not entirely resolved and would therefore benefit from further ${ }^{37}$ research. The Financial Stability Forum (FSF), which discussed the implementation of standards in some depth previously, ${ }^{38}$ has welcomed efforts on how financial regulation could be made more effective and efficient. $^{39}$

\section{Preliminary conclusions and an exemplification}

Further work concerning the regulatory framework for finite reinsurance arrangements is envisaged at different national and international organizations. Ultimately one has to answer the following question: which regulatory and supervisory framework is most appropriate to facilitate consumer protection and financial stability - and why? Our above considerations indicate that regulators and supervisors are and should be concerned with finite reinsurance for different reasons. This section provides preliminary conclusions with respect to the path for further advancing finite

\footnotetext{
${ }^{36}$ UK Cabinet Office (2007); Adler and Posner (2006); European Commission (2006).

${ }^{37}$ Oxera (2006, p. 32).

38 FSF (2001).

${ }^{39}$ Draghi (2006).
} 
reinsurance-related regulation and supervision. Furthermore, this section indicates how regulatory and supervisory efficiency could be evaluated.

This paper concludes that finite reinsurance regulation and supervision should be founded on a few clear and comprehensible rules and principles. Ideally these rules and principles would be applicable for insurance and reinsurance regulators/supervisors in all affected jurisdictions and therefore lead towards a regulatory and supervisory level playing field.

The notion that a few clear, comprehensible and worldwide applicable rules and principles would be adequate concerning finite reinsurance regulation and supervision takes the following considerations into account:

- Traceability: Only those potential regulatory/supervisory requirements that allow for a traceable cause-and-effect chain between regulation/supervision on the one hand and the envisaged effects on the other hand should be taken into consideration.

- Costs: Few and thereby also clear rules and principles concerning finite reinsurance would probably induce less direct costs $\left(C_{k D}\right)$.

- Harmonization: A small and concise set of agreed upon finite reinsurance-related rules and principles would make it easier to check and to verify the existence of a regulatory/supervisory level playing field among affected jurisdictions.

\section{Regulatory and supervisory efficiency considerations - exemplification on finite reinsurance}

This subsection introduces a preliminary approach to evaluating the benefits of actual and potential regulatory and supervisory measures. Three aspects that are relevant in the context of finite reinsurance are considered. For each considered issue, we discriminate and compare the efficiency of two regulatory/supervisory solutions. For example if the issue "regulatory/supervisory recognition of ceded risk" is considered one could discriminate between the following two solutions: discrete (binary) or gradual (risk-based) recognition.

Some aspects require considerations beyond the scope of regulators and supervisors. An example is the accounting treatment of finite reinsurance contracts. The accounting of insurance contracts is currently considered by the International Accounting Standards Board (IASB) ${ }^{40}$ within the so-called Phase II consultations.

\section{Accounting treatment}

From a regulatory/supervisory point of view, it could be an ideal world if the accounting treatment of both the ceding insurer and the reinsurer were identical and hence mirror each other. ${ }^{41}$ Mirroring enables easy and efficient verifications concerning any cross-border risk transfer. However, the recent IAIS guidance paper

\footnotetext{
${ }^{40}$ http://www.iasb.org/.

${ }^{41}$ IAIS (2006a, p. 13).
} 
on finite reinsurance explains why a perfect mirroring across borders is currently not achievable due to inconsistent assumptions and differing insurance risk transfer rules. ${ }^{42}$ Nevertheless, the harmonization of accounting standards is facilitated by the ongoing work within accounting standard setters like the IASB. Such efforts will most likely also smooth the progress of finite reinsurance-related harmonization.

\section{Regulatory/supervisory recognition of ceded risks}

Under the currently prevailing regulatory/supervisory regime the recognition of ceded risks is discrete (cf. also Figure 1). Some jurisdictions, for example the European Union under the envisaged Solvency II regime, aim at introducing a more risk-based approach. The latter would imply in other words rather gradual supervisory recognition of ceded risks: each additional portion of risk would lead to an increased supervisory allowance. Risk-related transparency could increase accordingly and thereby most likely also facilitate consumer protection and financial stability, since a determination of actual risk exposures at individual insurance and reinsurers would become easier.

\section{Freedom to arrange a finite contract}

Most jurisdictions do not require prior approval of finite reinsurance contracts. They rather request that applicable rules and principles be observed. It remains to be seen whether rules and principles or prior approval of each contract would be better suited to facilitate consumer protection and financial stability. For the time being, this paper assumes that both solutions could have a positive impact on consumer protection and financial stability. However, further research might indicate that financial stability could be better supported by a regulatory/supervisory framework based on principles and rules, since it is reasonable to assume that prior approval would diminish the ability of insurers and reinsurers to provide, among other things, innovations that enhance appropriate risk management solutions.

Figure 6 provides a template that summarises our preliminary efficiency considerations. Ongoing and/or foreseeable developments that could have an impact on specific aspects of current supervisory efficiency are presented as an outlook in the last column.

It remains a challenging task to quantify the benefits of regulation and supervision. Therefore, a direct comparison of rectified supervisory solutions that are available for specific issues could improve cost-benefit considerations. Despite the need for further research in this area it seems to be reasonable to draw, in the light of our preliminary efficiency and cost-benefit considerations, the following conclusion: finite reinsurancerelated regulation should rather be concise. Moreover, this paper concludes that regulatory requirements concerning finite reinsurance (and beyond) should themselves meet certain transparency requirements. A specific elaboration on the precise intended 


\begin{tabular}{|c|c|c|c|c|c|}
\hline & & \multicolumn{2}{|c|}{$\begin{array}{l}\text { Potential } \\
\text { impact on: }\end{array}$} & \multirow{3}{*}{$\begin{array}{l}\text { Regulatory and } \\
\text { supervisory } \\
\text { efficiency }\end{array}$} & \multirow{3}{*}{ Outlook } \\
\hline \multicolumn{2}{|c|}{ Examples } & \multirow{2}{*}{ 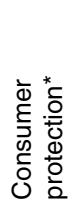 } & \multirow{2}{*}{ 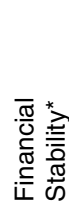 } & & \\
\hline Issue & Design & & & & \\
\hline \multirow{2}{*}{ 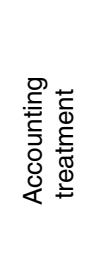 } & Mirroring & + & + & \multirow{2}{*}{$\begin{array}{l}\text { In the light of cross-border } \\
\text { transactions an increased } \\
\text { comparability of accounted } \\
\text { results would facilitate } \\
\text { regulatory and supervisory } \\
\text { efficiency. }\end{array}$} & \multirow{2}{*}{$\begin{array}{c}\text { Worldwide mirroring } \\
\text { seems to be unrealistic. } \\
\text { However, steps towards a } \\
\text { convergence, e.g. } \\
\text { work by IASB, of } \\
\text { accounting systems } \\
\text { are observable. }\end{array}$} \\
\hline & Differing & 0 & 0 & & \\
\hline \multirow{2}{*}{ 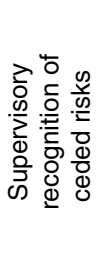 } & Discrete & - & - & \multirow{2}{*}{$\begin{array}{l}\text { A gradual recognition of ceded } \\
\text { risks would increase the } \\
\text { transparency of the risk } \\
\text { exposure. It remains to be } \\
\text { seen how gradual } \\
\text { recognition would } \\
\text { affect fraud detection. }\end{array}$} & \multirow{2}{*}{$\begin{array}{c}\text { The envisaged Solvency II } \\
\text { framework is an example } \\
\text { for the development } \\
\text { towards a risk-based } \\
\text { and therefore rather } \\
\text { gradual, recognition } \\
\text { of ceded risks. }\end{array}$} \\
\hline & Gradual & + & + & & \\
\hline \multirow{2}{*}{ 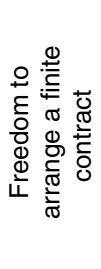 } & $\begin{array}{l}\text { Prior } \\
\text { Approval }\end{array}$ & + & + & \multirow{2}{*}{$\begin{array}{l}\text { Appropriate guiding principles } \\
\text { associated with sufficient } \\
\text { supervision would probably } \\
\text { require fewer } \\
\text { resources for both } \\
\text { regulators/ supervisors and } \\
\text { regulated/supervised entities. }\end{array}$} & \multirow{2}{*}{$\begin{array}{l}\text { Prior approval would most } \\
\text { probably reduce the } \\
\text { ability to introduce } \\
\text { innovations. Moreover, } \\
\text { it remains to be seen } \\
\text { to which extent prior } \\
\text { approval reduces fraud. }\end{array}$} \\
\hline & $\begin{array}{l}\text { Guiding } \\
\text { principles }\end{array}$ & + & + & & \\
\hline
\end{tabular}

Figure 6. Preliminary considerations concerning regulatory/supervisory efficiency.

*A positive impact is characterized by a "+" whereas a "-" denotes an adverse and " 0 " a rather neutral effect.

impact of a regulatory requirement could be a first step. At the same time, it might be reasonable for regulators and supervisors to provide a traceable economic explanation of exactly how and to what extent a regulatory and/or supervisory measure would support the intended aim.

\section{Summary and outlook}

This paper illuminates the issue of regulating and supervising finite reinsurance from different perspectives. The prevailing methodology of classifying finite reinsurance 
contracts is thereby revisited. In this regard, specific requirements concerning catastrophe insurance are displayed. Furthermore, the question of effectiveness and efficiency regarding finite reinsurance regulation is addressed. In doing so, this paper also provides a preliminary analysis on the subject of potential cost-benefit considerations. An evaluation of regulatory and supervisory efficiency is the aim of the latter.

In almost each jurisdiction, the issue of how to regulate and how to supervise finite reinsurance is also dependent on the specific political and legal framework. Consumer protection and financial stability are elaborated on to some degree in this paper, since both aspects are typically regarded as a rationale for insurance regulation and supervision. The aim of this paper is thereby to provide some preliminary indications as to whether specific regulatory and supervisory measures would facilitate consumer protection and financial stability. At this point the specification of a traceable causeand-effect chain is advocated, a cause-and-effect chain that provides a clear link between the regulatory and supervisory measures on the one hand and the intended aim (e.g. consumer protection and/or financial stability) on the other hand. This paper therefore proposes that each regulatory and supervisory measure could be based on a traceable economic justification.

In the light of the just mentioned considerations, this paper concludes that regulatory and/or supervisory measures concerning finite reinsurance should be based on few concise and worldwide applicable rules and principles.

The IAIS, which provides a set of insurance-specific conventions, the so-called Insurance Core Principles (ICPs), ${ }^{43}$ is in a position to facilitate supervisory efficiency and the path towards regulatory harmonization in the field of finite reinsurance and beyond.

More research could provide additional analysis on the quantification of regulatory and supervisory benefits. However, this paper indicates a preliminary solution regarding a comparative evaluation of supervisory efficiency. Furthermore, it could be beneficial to extend the above considerations beyond finite reinsurance. In addition to that it could be an issue for the future to demand not only a clear and logic link between specific measures and the intended outcome but also an empirical foundation.

\section{References}

Adams, M.B. and Tower, G.D. (1994) 'Theories of regulation: some reflections on the statutory supervision of insurance companies in Anglo-American countries', The Geneva Papers on Risk and Insurance - Issues and Practice 71(2): 156-177.

Adler, M.D. and Posner, E.A. (2006) New Foundations for Cost-Benefit Analysis, Cambridge, MA: Harvard University Press.

American Academy of Actuaries (2005) Risk Transfer in P \& C Reinsurance: Report to the Casualty Actuarial Task Force of the National Association of Insurance Commissioners, American Academy of Actuaries, Committee on Property and Liability Financial Reporting, Washington, DC.

Aschenbrenner-von Dahlen, S. (2006) 'Finite reinsurance: some insights into the development of regulatory and supervisory provisions', PROGRES (Programme on Regulation, Supervision and Legal Issues) 43(June): $12-16$.

\footnotetext{
${ }^{43}$ Kawai (2005); Hohlfeld (2004); IAIS (2003).
} 
Avesani, R.G. (2005) FIRST: A Market-Based Approach to Evaluate Financial System Risk and Stability, IMF Working Paper 232, December, Washington, DC.

Barry, M.J. (2004) Finite Risk Reinsurance (November), Special Report, Fitch Ratings, New York.

BIS (2005) Bank for International Settlements Quarterly Review (December), Basel: BIS.

von Bomhard, N. and Frey, C. (2006) 'Future financial frameworks - essentials for risk-based capital management', The Geneva Papers on Risk and Insurance - Issues and Practice 31: 46-56.

Borio, C. (2003) Towards a macroprudential framework for financial supervision and regulation? BIS Working Papers, No. 128, Basel.

Caruana, J. (2005) 'Is supervision keeping pace with innovation?' Geneva Papers on Risk and Insurance, Issues and Practice 30: 11-18.

Casualty Actuarial Society (2005) Risk Transfer Testing of Reinsurance Contracts: Analysis and Recommendations, Arlington, VA: CAS Research Working Party on Risk Transfer Testing.

Culp, C.L. and Heaton, J.B. (2005) 'The uses and abuses of finite risk reinsurance', Journal of Applied Corporate Finance 17: 18-31.

Das, U.S., Davies, N. and Podpiera, R. (2003) Insurance issues in financial soundness, IMF Working Paper 138, July, Washington, DC.

Diamond, D.W. and Dybvig, P.H. (1983) 'Bank runs, deposit insurance and liquidity', Journal of Political Economy 91: 401-419.

Draghi, M. (2006) Statement, Chairman of the Financial Stability Forum, International Monetary and Financial Committee Meeting, 17 September 2006, Singapore, from http:/www.fsforum.org/press/ IMFC_Statement_September_2006.pdf, accessed 01 October 2006.

EU Directive (2005) DIRECTIVE 2005/68/EC of the European Parliament and of the Council of 16 November 2005 on reinsurance and amending Council Directices 73/239/EEC, 92/49/EEC as well as Directives 98/78/ $E C$ and 2002/83/EC, Brussels.

European Commission (2006) 'A Strategic Review of Better Regulation in the European Union, November 06', from http://ec.europa.eu/governance/impact/key_en.htm, accessed 28 January 2007.

Fender, I. and Wooldridge, P. (2005) 'Impact of Hurricane Katrina on the reinsurance industry', BIS Quarterly Review (December): 13-14.

Fromme, H. (2006) [German title: Finanzrück-Regeln werden klarer] Financial Times Germany 19(October): 17.

FSF (2001) Final Report of the Follow-Up Group on Incentives to Foster Implementation of Standards, Basel: FSF, 21 August.

Hohlfeld, K. (2004) 'Current priorities in international standard setting on insurance supervision', The Geneva Papers on Risk and Insurance - Issues and Practice 29: 78-86.

IAIS (2003) Insurance Core Principles, Principles No 1, Singapore: IAIS, October.

IAIS (2004) Enhancing Transparency and Disclosure in the Reinsurance Sector, Basel: Task Force Re, IAIS, March.

IAIS (2005) Global Reinsurance Market Report 2005, Basel: IAIS, December.

IAIS (2006a) Guidance Paper on Risk Transfer, Disclosure and Analysis of Finite Reinsurance, IAIS Guidance Paper No. 11, Beijing, October 26.

IAIS (2006b) Global Reinsurance Market Report 2006, Basel: IAIS, November.

IMF (2003) Financial Soundness Indicators - Background Paper, Washington, DC: IMF.

Kawai, Y. (2005) 'IAIS and recent developments in insurance regulation', The Geneva Papers on Risk and Insurance - Issues and Practice 30: 29-33.

Kielholz, W.B. and Nebel, R. (2005) 'Improving regulatory governance', The Geneva Papers on Risk and Insurance - Issues and Practice 30: $34-42$.

Knight, M.D. (2006) 'Marrying the Micro- and Macroprudential Dimensions of Financial Stability: Six Years on', from http://www.bis.org/speeches/sp061005.htm, accessed 27 January 2007.

Mørup, L. (2006) 'Transparency in the reinsurance sector - An IAIS initiative', in M. Crisell (ed) International Reinsurance Review 2006/07, Colchester, UK: Euromoney Yearbooks, pp. 19-22.

NAIC (2006) Current Issues: Finite Reinsurance, Kansas City, MO: NAIC, from http://www.naic.org/topics/ topic_finite_re.htm, accessed 01 October 2006.

Nebel, R. (2002) 'The case for liberal reinsurance regulation', The Geneva Papers on Risk and Insurance Issues and Practice 27: 113-121. 
O'Brien, T. (2005) 'Deal between Berkshire and former AIG chief under investigation', International Herald Tribune, Thursday, March 31.

OECD (2006) Cutting Red Tape: National Strategies for Administrative Simplification, Paris: OECD.

Oxera (2006) A framework for assessing the benefits of financial regulation, Report prepared for the Financial Services Authority, Oxford.

Peltzman, S. (1976) 'Towards a more general theory of regulation', Journal of Law and Economics 19: 211-240

Rees, R., Gravelle, H. and Wambach, A. (1999) 'Regulation of insurance markets', The Geneva Papers on Risk and Insurance - Theory 24(1): 55-68.

Renda, A. (2006) Impact Assessment in the EU: The State-of-the-Art and the Art of the State, Brussels: Center of European Policy Research.

Royal Commission (2003) 'The Failure of HIH Insurance', from http://www.hihroyalcom.gov.au/ finalreport/, accessed 01 October 2006.

Schiro, J. (2006) 'External forces impacting the insurance industry: Threats from regulation', The Geneva Papers on Risk and Insurance - Issues and Practice 31: 25-30.

Schinasi, G.J. (2004) Defining financial stability, IMF Working Paper 04/187, Washington, DC.

Stigler, G.J. (1971) 'The theory of economic regulation', Bell Journal of Economics and Management Science 2(3): 3-21.

Trichet, J.-C. (2005) 'Financial stability and the insurance sector', The Geneva Papers on Risk and Insurance - Issues and Practice 30: 65-71.

UK Cabinet Office (2007) 'Regulatory Impact Assessment Guidance', from http://www.cabinetoffice. gov.uk/regulation/ria/ria_guidance/index.asp, accessed 28 January 2007.

World Bank and IMF (2005) Financial Sector Assessment: A Handbook, Washington, DC: World Bank and IMF.

Zweifel, P. and Eisen, R. (2000) Insurance Economics [Versicherungsökonomie], Berlin Heidelberg, New York: Springer-Verlag.

\section{About the Author}

Sebastian von Dahlen, as a Principal Administrator, is responsible for the field of reinsurance at the Secretariat of the International Association of Insurance Supervisors (IAIS), which is hosted within the Bank for International Settlements (BIS), Switzerland. He studied economics and natural sciences at different universities, including a period as research fellow at the University of California at Berkeley. Among his (re-)insurance-related practical experiences are a stay at the Colonia Insurance Company in New York City and a position at the Federal Financial Supervisory Authority (BaFin). 